\title{
Uncertainty and Fuzzy Decisions in Earthquake Risk Evaluation of Buildings
}

\author{
Akkachai Ketsap $^{1}$, Chayanon Hansapinyo ${ }^{2, *}$, Nopadon Kronprasert ${ }^{3}$ \\ and Suchart Limkatanyu ${ }^{4}$
}

1 Department of Civil Engineering, Chiang Mai University, Thailand

2 Center of Excellence in Natural Disaster Management, Department of Civil Engineering, Chiang Mai University, Thailand, Chiang Mai University, Thailand

3 Excellence Center in Infrastructure Technology and Transportation Engineering (ExCITE), Chiang Mai University, Thailand

4 Department of Civil Engineering, Faculty of Engineering, Prince of Songkla University, Thailand *E-mail:chayanon@eng.cmu.ac.th (Corresponding author)

\begin{abstract}
The Northern region of Thailand has been considered as one of the seismic risk zones. However, most existing buildings in the area had been designed and constructed based on old building design codes without seismic consideration. Therefore, those buildings are required to upgrade based on earthquake building damage risk evaluation. With resource limitations, it is not feasible to retrofit all buildings in a short period. In addition, the results of the risk evaluation contain uncertain inputs and outputs. The objective of this study is to prioritize building retrofit based on fuzzy earthquake risk assessment. The risk assessment of a building was made considering the risk factors including (1) building vulnerability, (2) seismic intensity and (3) building values. Then, the total risk was calculated by integrating all the risk factors with their uncertainties using a fuzzy rule based model. An example of the retrofit prioritization is shown here considering the three fuzzy factors. The ranking is hospital, temple, school, government building, factory and house, respectively. The result helps decision makers to screen and prioritize the building retrofitting in the seismically prone area.
\end{abstract}

Keyword: Fuzzy logic, retrofit prioritization, seismic risk assessment.

ENGINEERING JOURNAL Volume 23 Issue 5

Received 29 August 2018

Accepted 25 June 2019

Published 30 September 2019

Online at http://www.engj.org/

DOI:10.4186/ej.2019.23.5.89 


\section{Introduction}

Earthquake is a natural disaster that can be tremendously destructive in a vast area of massive ground shaking. Among the earthquake consequences e.g. landslide, flood, fire, tsunami, building collapse is claimed as the majority of loss of life. The loss of life can be minimized through the construction of buildings for seismic resistance. Hence, new improved seismic building design codes have been continuously emerged based on the past experiences and lessons learnt from the failure. Unfortunately, for a low or moderate seismicity area, the long return period of a big earthquake leads to low awareness of preparedness. This results to non-seismic design and construction until a new occurrence of earthquake [1].

Considering building collapse as a majority of the earthquake loss, a mitigation measure has been then primary focused on high resilience building [2]. Construction of new buildings can be seismically controlled with use of newly developed building regulation. In addition, seismic strengthening of existing under-seismic designed buildings is also concurrently implemented. The mitigation will eventually bring all buildings in the inventory to conform to seismic performance demand. However, the strengthening of all buildings is subjected to economical limitation. Hence, risk assessment is necessary to identify risk level of every buildings and then prioritization procedure is developed for the incremental strengthening.

To determine the building quality, which is a variable for the earthquake risk assessment, in a large area, exterior rapid inspection is required considering several of the measured and calculated factors such as the storey number, cantilever extension, soft storey, weak storey, building quality, pounding effect, hill-slope effect, and peak ground velocity. Rapid interior inspection was performed by Sen [3] considering building height, story height ratio, cantilever extension ratio, moment of inertia, column and shear wall area percentages, and the number of frames and the area of influence. The rapid inspection is considered acceptable as a rough estimation giving an overview for the earthquake mitigation planning. Hence, the variable contains a level of uncertainty.

Earthquake hazard is also impossible to accurately estimate for the magnitude and location. Erdik [4] performed the earthquake risk assessment considering the variations including three main factors eg. earthquake hazard, fragility/vulnerability and inventory of assets exposed to hazard. These factor are uncertain in nature and difficult to measure. In this complicated evaluation, sophisticated risk assessments are often made. Ellingwood [5] assessed the earthquake risk of building structures pertaining to the probability-based method. In his work, the inherent randomness and modelling uncertainty in forecasting building performance were quantitatively examined.

Early application of fuzzy logic theory to manipulate the vague information was proposed by Zadeh [6] and then the theory has been become widely adopted in many applications including the earthquake risk assessment [7]. Deb and Kumar [8] qualitatively conducted assessment of seismic damage in reinforced concrete buildings by applying the fuzzification method. The fuzzy linguistic variable was inverted to the damage index that corresponding to the damage state. The damage index was defined from 0 to 1 indicating the damage level from non-structural damage (no building damage) to building collapse, respectively. Sen [9] proposed the fuzzy logic method for building earthquakes assessment satisfying multiple performance objectives including both quantitative and qualitative information sets. D'Urso et al. [10] proposed fuzzy analytic hierarchical model to support the decision-making activity for emergency management in the territory of L'Aquila under the April 9th 2009 earthquake. Haoxiang et al. [11] showed the applicability of fuzzy set methodology to seismic damage assessment in reinforced concrete structures. Boutaraa et al. [12] proposed fuzzy set to define possible and less probable vulnerability classes of buildings by the trapezoidal membership functions. Vahdat et al. [13] proposed fuzzy multi-criteria decision making (MCDM) with an aggregated fuzzy seismic risk index (FSRi) which has potential for mitigating the exposure of cities in Iran to access seismic risk. The result helped decision makers to screen and prioritize multiple regions in seismically prone areas.

Figure 1 shows the Venn diagram illustrating the three risk factors including the building vulnerability, site seismic hazard and importance of building (building occupancy type). The overlapping area or intersection of the factors represents the set of all seismic risk. Finally, the risk mitigation is made on the overlapped area. From the above literature review, past researches in the field of seismic risk assessment have been done mainly for building damage considering the building vulnerability and the earthquake hazard. In this paper, seismic risk assessment approach is hence proposed with the inclusion of the building value. Chiang Rai municipality area, located in the Northern region of Thailand was selected for the study. The complex problem of risk assessment can be drawn up in the hierarchical structure, as shown in Fig. 2. From the figure, Level 1 of the hierarchy is the seismic risk or the total risk of the analysis. Building damageability (Level 2) was first determined considering the site seismic hazard (Level 3) and building vulnerability (Level 
3). Then, the building damageability was combined with the building importance for the total seismic risk. For the analysis result with the total seismic risk score, ranking for the seismic retrofitting prioritization can be made.

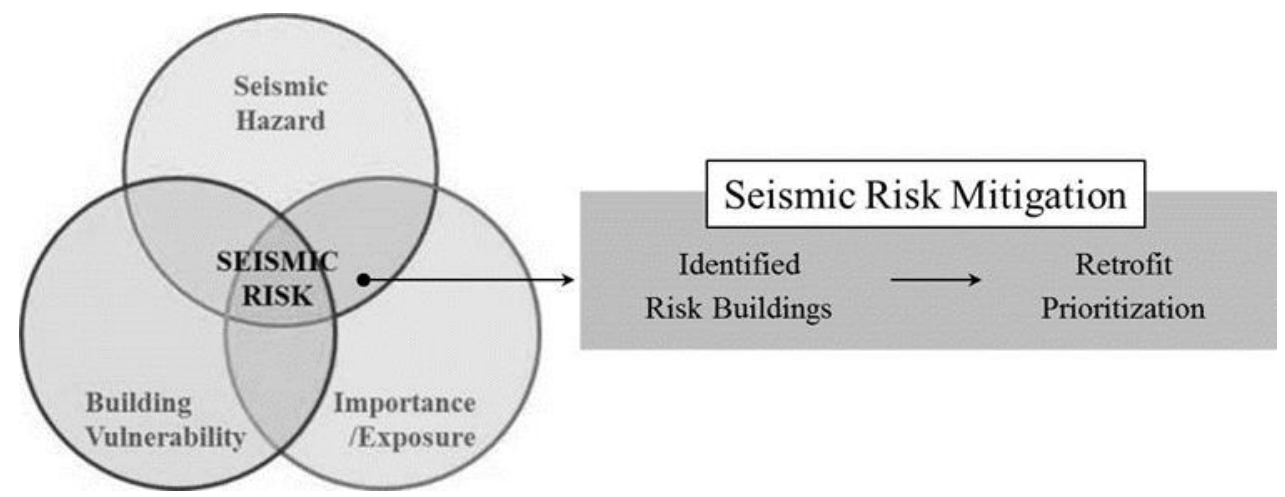

Fig. 1. Venn diagram for earthquake risk assessment [14].

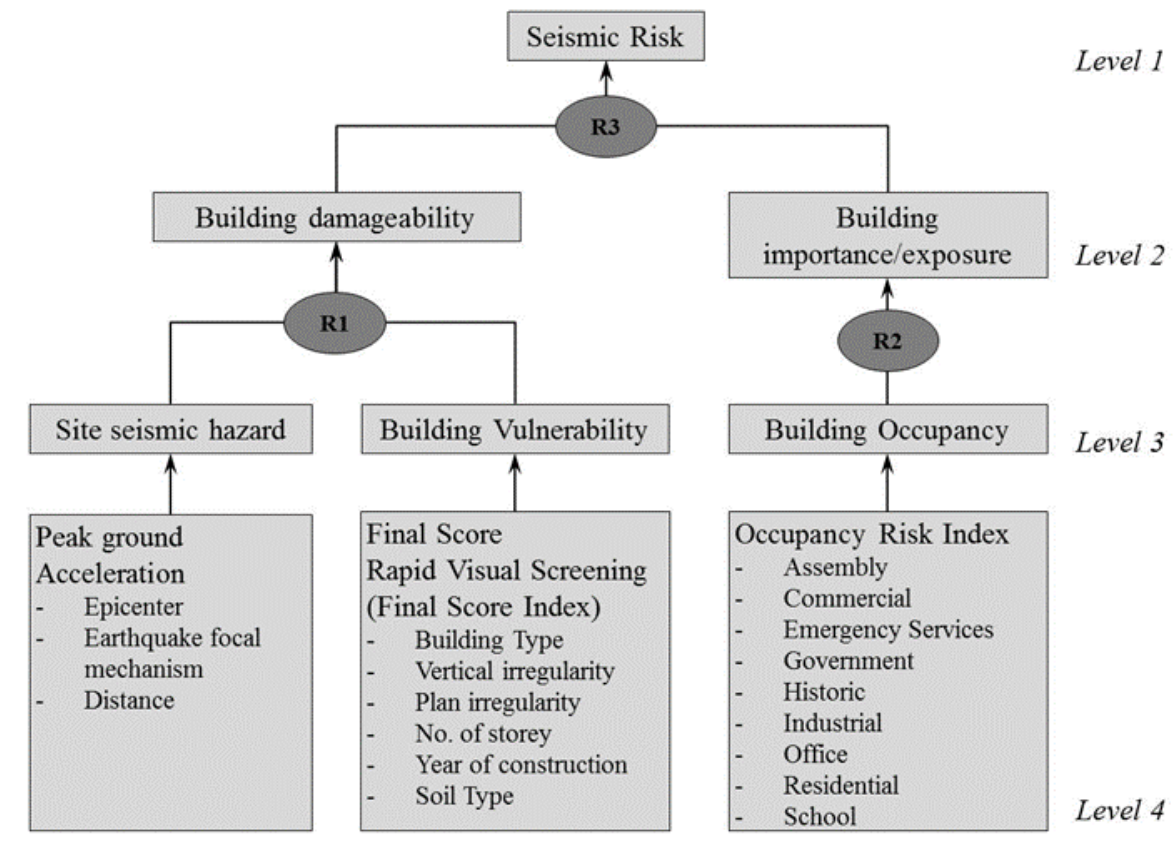

Fig. 2. Hierarchical building risk assessment from earthquake hazard.

\section{Seismic Risk in the Study Area}

Chiang Rai province is one of the most earthquake risk area consisting of Mae Chan - Chiang Saen fault and Phayao fault that can cause an earthquake of magnitude 6.0 - 6.5 on the Richter scale [15]. The maximum peak ground acceleration from the 475-years return period earthquake is approximately more than $0.2 \mathrm{~g}$ on the solid rock [16-17] as shown in Fig. 3. The recent big earthquake with magnitude of 6.3 was occurred on May 5, 2014. The epicenter of the earthquake was about 7.4 kilometers depth and 27 kilometers southwest of Chiang Rai city. The earthquake was recorded as strong, shaking both northern Thailand and neighbouring Myanmar and Laos, Thailand. Saicheur and Hansapinyo [7] reported that more than 16,000 buildings were damaged. Six hundred buildings were classified as serious damage level. It caused approximately $\$ 28$ Million in building damage loss. Although, it was the strongest earthquake ever recorded in Thailand, the consequence losses were quite low compared to other similar earthquakes. This is due to the fact that the epicentre was far from the central business area. As estimated by Saicheur and Hansapinyo [18], with an assumed magnitude of 5 and $10 \mathrm{~km}$ depth on a fault near the city, $24.79 \%$ of the buildings in Chiang Rai Municipality could be damaged. 


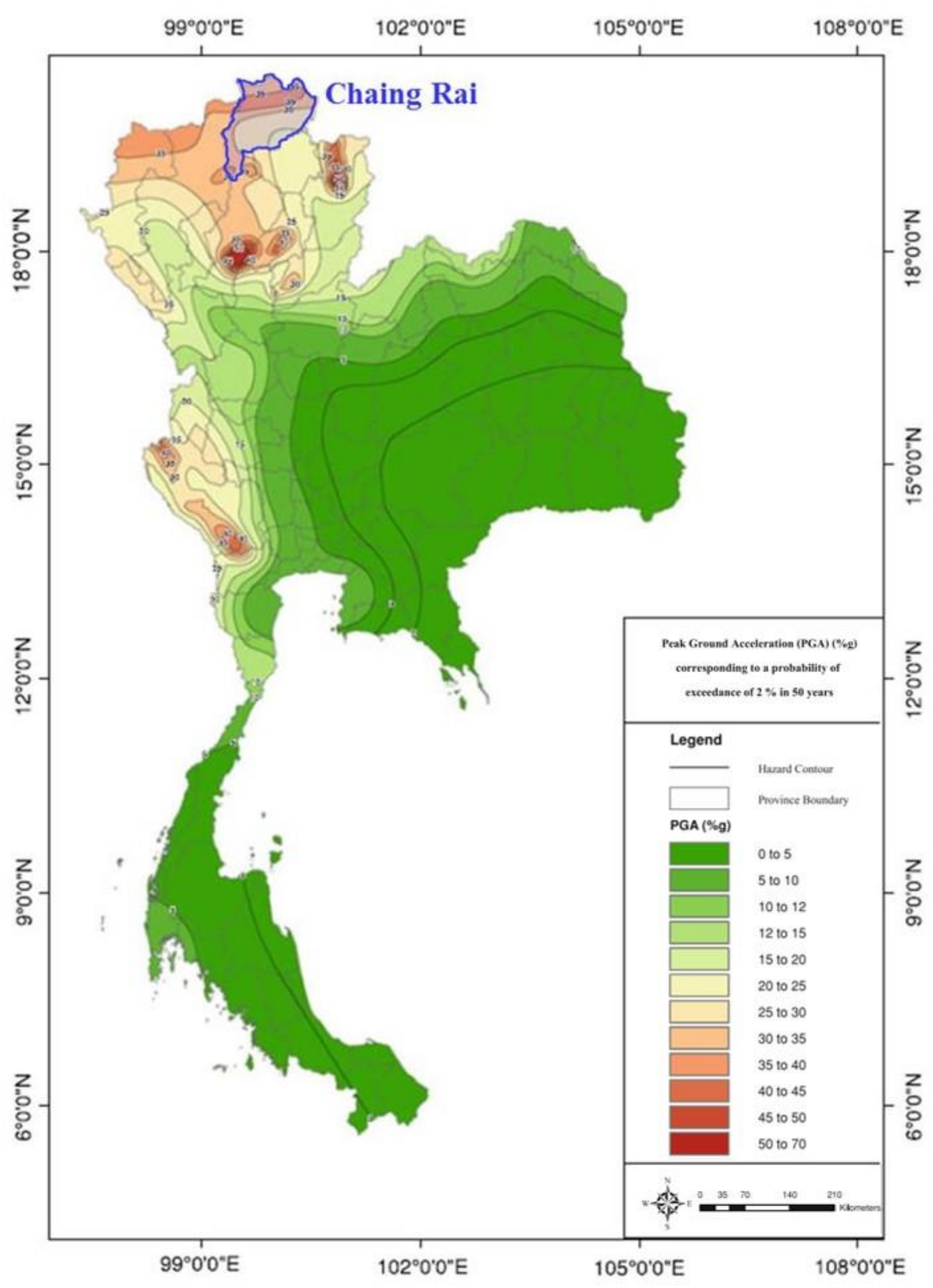

Fig. 3. Thailand hazard maps for PGA corresponding to a probability of exceedance of $2 \%$ in 50 years [17].

With the high seismic hazard, Chiang Rai municipality was selected for the study. The area located on the central of Chiang Rai province covering $79.3 \mathrm{sq} . \mathrm{km}$. There are approximately 46,775 buildings. Most of them are classified as C3 or Low-rise reinforced concrete frames with unreinforced masonry, infilled walls, as shown in Table 1 [19-20]. They are mostly occupied for residential and commercial purposes. 
Table 1. Structural type of buildings in the study area.

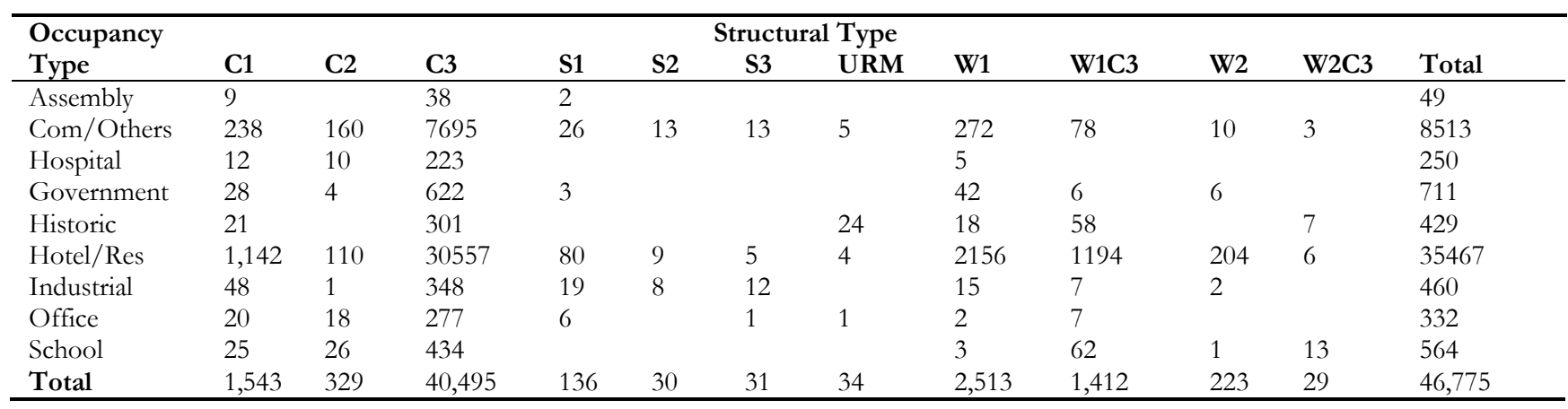

where

C1 is concrete moment-resisting frame buildings

$\mathrm{C} 2$ is concrete shear-wall buildings

C3 is concrete frame buildings with unreinforced masonry infill walls

S1 is steel moment-resisting frame buildings

S2 is braced frame buildings

S3 is light metal buildings

URM is unreinforced masonry bearing-wall buildings

W1 is light wood-frame buildings smaller than or equal to $460 \mathrm{~m}^{2}$

W2 is light wood-frame buildings larger than $460 \mathrm{~m}^{2}$

W1C3 is combination structure light wood-frame and concrete frame buildings with unreinforced masonry infill walls smaller than or equal to $460 \mathrm{~m}^{2}$

W2C3 is combination structure light wood-frame and concrete frame buildings with unreinforced masonry infill walls larger than $460 \mathrm{~m}^{2}$

\section{Fuzzification of the Input Variables}

\subsection{Theory of Fuzzy Logic}

The professional judgments may be a verbal statement with vagueness or fuzziness. The example of vagueness in the earthquake risk assessment can be "The building is moderately vulnerable" or "The building is very important" or "The peak ground acceleration is high". Risk analysis problems contain a mixture of quantitative and qualitative data. Therefore, the analysis has widely adopted Fuzzy logic providing a language with semantics to translate qualitative knowledge into numerical reasoning. The strong benefit of fuzzy logic is that it can integrate descriptive or linguistic knowledge and numerical data to fuzzy model and use approximate reasoning algorithms to propagate the uncertainties throughout the decision process. A fuzzy set describes the relationship between an uncertain quantity in set and membership function which ranges between 0 and 1 as shown in Eq. (1).

$$
\mu_{\tilde{A}}(x)= \begin{cases}1, & x \in \tilde{A} \\ 0, & x \notin \tilde{A}\end{cases}
$$

where the symbol $\mu_{\tilde{A}}(x)$ gives the indication of an unambiguous membership of element $x$ in set $\tilde{A}$, and $\in$ and $\notin$ denote "contained in" and "not contained in", respectively. The membership function is a critical important input for the fuzzy logic system to translate the qualitative description into a quantitative measure. Several geometric membership functions have been widely adopted, such as triangular, trapezoidal and Sshaped membership functions. However, triangular and trapezoidal membership functions are the most frequently used in seismic risk assessment practice [11], as shown in Eqs. (2) - (3), respectively.

(1) Triangular membership function 


$$
\text { Triangular }(x: a, b, c)= \begin{cases}0 & x<a \\ (x-a) /(b-a) & a \leq x<b \\ (c-x) /(c-b) & b \leq x<c \\ 0 & x>c\end{cases}
$$

(2) Trapezoidal membership function

$$
\text { Trapezoidal }(x: a, b, c, d)= \begin{cases}0 & x<a \\ (x-a) /(b-a) & a \leq x<b \\ 1 & b \leq x<c \\ (d-x) /(d-c) & c \leq x<d \\ 0 & x \geq d\end{cases}
$$

From Eq. (2), "a" represents the minimum unlikely value, "b" represents the most likely values and "c" represents the maximum unlikely value. For Eq. (3), "a" represents the minimum unlikely value, "b" and "c" equally represent the most likely values and "d" represents the maximum unlikely value.

The fuzzy inference system (FIS) contains three basic steps, as described by Zadeh [6] and shown in Fig. 4. First, linguistic variables are transformed into numerical variables. This step is normally called fuzzification. Second, variables inference relationships between the variables are integrated using IF-THEN rules (reasoning algorithms). Finally, defuzzification which is the process of producing a quantifiable result in Crisp number is performed. The crisp outputs were defuzzified using the weighted average method, as expressed in Eq. (4). The weighted average method was formed by weighting each membership function in the output considering its respective maximum membership value [20].

$$
Z^{*}=\frac{\sum_{i=1}^{N} \mu_{\tilde{c}}\left(Z_{i}\right) \cdot Z_{i}}{\sum_{i=1}^{N} \mu_{\tilde{c}}\left(Z_{i}\right)}
$$

where $\Sigma$ denotes the algebraic sum and $Z_{i}$ is the centroid of each symmetric membership function, $\mu_{\tilde{c}}\left(Z_{i}\right)$ is the output fuzzy value in fuzzy set $i$, and $Z^{*}$ is the defuzzified value. The application of fuzzy logic on the seismic risk assessment in this paper is described as follows.

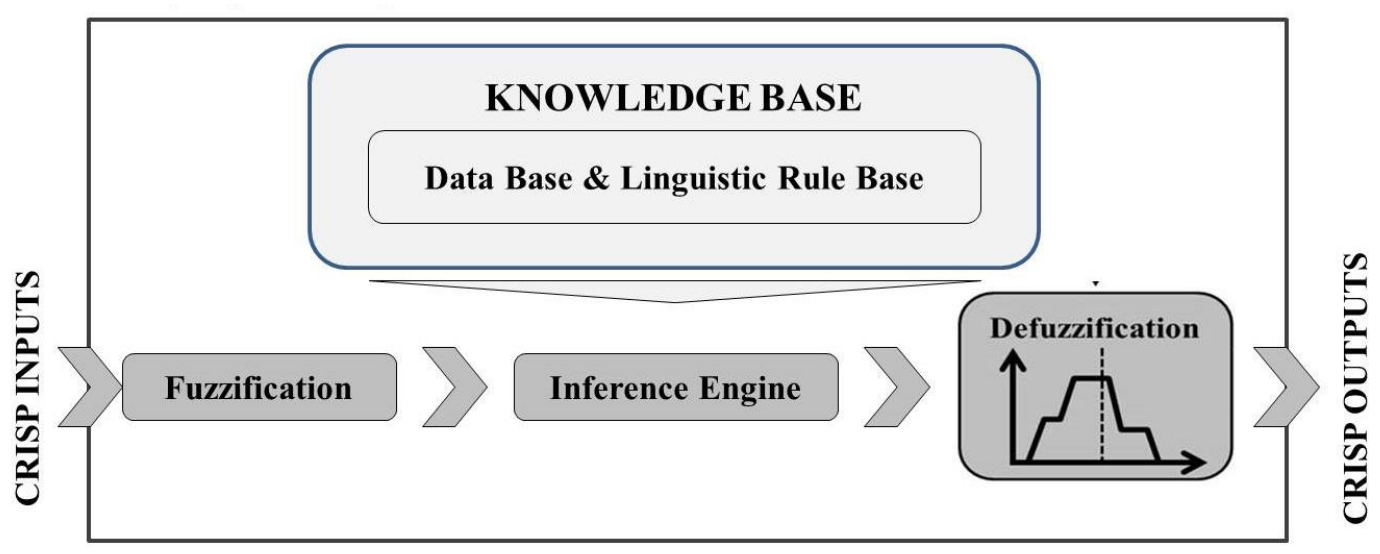

Fig. 4. A General scheme of a fuzzy logic decision system. 


\subsection{Building Vulnerability}

Seismic building vulnerability assessment can be performed by using various approaches depending on the purposes of the evaluation. As it is impossible to perform more advanced and detailed evaluation individually for all building stocks, this study adopted the assessment method based on sidewalk screening. Adopted from FEMA154-155 [19-20], the building vulnerability was identified from rapid visual screening survey. The method is classified as Tier1 seismic performance evaluation of existing buildings. The rapid visual screening firstly considers basic score considering structural type. Then, the score is modified for the final score (S) based on other seismic characteristics of the building, e.g. building height, building age, soil condition, plan irregularity. The final score (S) obtained implicitly represents seismic performance or damage grade. Nanda and Majhi [21] suggested that the structure damage could be categorized in different grades depending on their impacts on the seismic strength of the building, as shown in Table 2. A building with a higher final score performs better seismic performance with a lower damage grade. The severity of damage is ranged from Grade 1: No damage to Grade 5: Destruction.

Table 2. Structural scores with damaged potential [21].

\begin{tabular}{ll}
\hline $\begin{array}{l}\text { RVS Final } \\
\text { Score }(\mathrm{S})\end{array}$ & Damage Potential \\
\hline $\mathrm{S}<0.3$ & High probability of Grade 5 damage; Very high probability of Grade 4 Damage \\
$0.3<\mathrm{S}<0.7$ & High probability of Grade 4 damage; Very high probability of Grade 3 Damage \\
$0.7<\mathrm{S}<2.0$ & High probability of Grade 3 damage; Very high probability of Grade 2 Damage \\
$2.0<\mathrm{S}<2.5$ & High probability of Grade 2 damage; Very high probability of Grade 1 Damage \\
$\mathrm{S}>2.5$ & Probability of Grade 1 damage \\
\hline
\end{tabular}

According to the relationship between the RVS final score and damage potential in Table 2, the building vulnerability was fuzzified into five fuzzy sets as "Weak, W", "Very Weak, VW , "Moderate, M", "Strong, S" and "Very Strong, VS", respectively. Triangular and trapezoidal fuzzy models were used to relate the linguistic vulnerability levels and the final scores, as shown in Table 3 and Fig. 5. From the figure, the building vulnerability can be partially classified for the final scores other than the most likely/unlikely values. For example, for the RVS final score of 0.5 , the building vulnerability can be classified as the combination of the "Weak, W" and "Moderate, M".

Table 3. Building vulnerability fuzzy number.

\begin{tabular}{cc}
\hline Linguistic Parameter & Transformation \\
\hline Very Weak, VW & $\operatorname{trimf}(0,0,0.3)$ \\
Weak, W & $\operatorname{trimf}(0,0.3,0.7)$ \\
Moderate, $M$ & $\operatorname{trimf}(0.3,0.7,2)$ \\
Strong, S & $\operatorname{trimf}(0.7,2,2.5)$ \\
Very Strong, VS & $\operatorname{trapmf}(2,2.5,7,7)$ \\
\hline
\end{tabular}




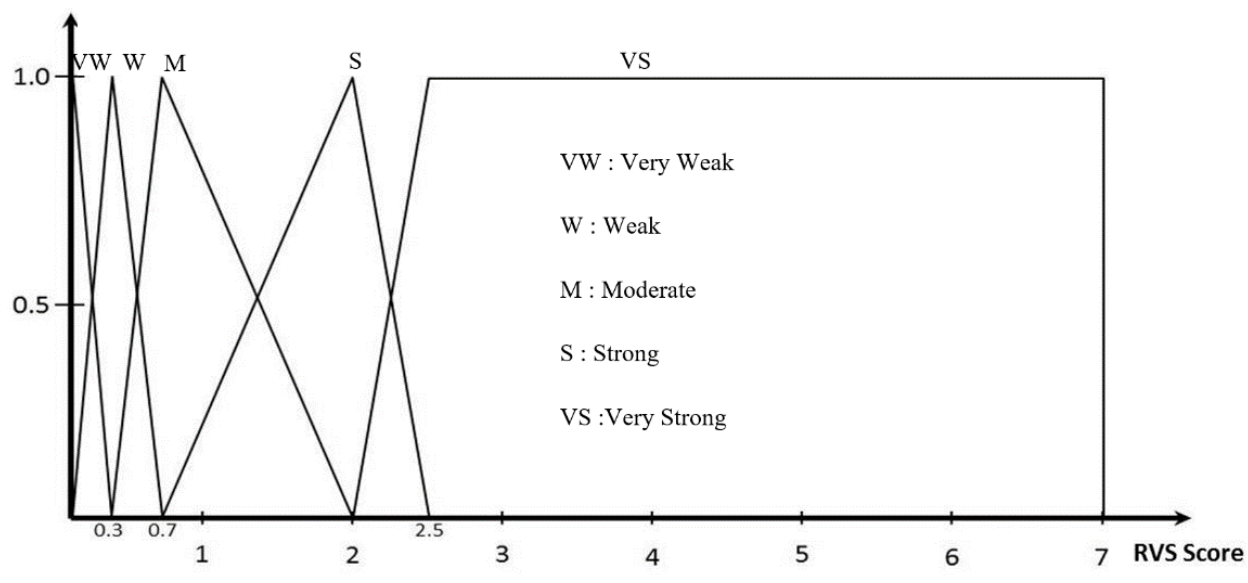

Fig. 5. Building vulnerability fuzzy model.

\subsection{Seismic Hazard}

Based on the existing size and mechanism of a fault nearest to the study area and the seismicity in this zone, the epicenter (UTM 583628N, 2203873E) on Mae Lao fault was selected. The hypocenter was about 10 kilometers underground with the magnitude of 5.0. Spatial Peak ground acceleration (PGA) was then estimated using the attenuation relationship proposed by Youngs et al., [22]. For the assumed earthquake event and the attenuation model, Fig. 6 shows the peak ground acceleration distribution in the study area. The acceleration was in the range of $0.104 \mathrm{~g}$ to $0.241 \mathrm{~g}$ in the earthquake scenario, which is in the same intensity range investigated by the past research [23].

The peak ground acceleration directly vibrates buildings and generates the lateral deformation of the buildings. The uncertainty in the evaluation of the PGA intensity exists as the different buildings response differently even under the same PGA. Hence, in this study, the severity of the PGA is represented based on the damage level. FEMA [24] established the structural capacity curve for different structural types shown in Table 1. Using the capacity curve and the estimated spatial ground acceleration level (Fig. 6), the seismic deformation of buildings $\left(d_{e}\right)$ in the area was obtained. Next, the fragility curves were used to determine the damage probability (Step 1 in Fig. 7). The damage probability was determined for the PGA(g) of 0.0-0.3g covering the range of the estimated PGA (Step 2 in Fig. 7). Finally, the probability of damage states were applied in PGA(g) fuzzy model (Step 3 in Fig. 7). The Fuzzy linguistic terms of the PGA intensity are classified from the "Very Low" to "Intensive" based on the accumulated damage state as follow

"Very Low, VL" : the accumulated damage state in slight - complete is less than $30 \%$

"Low, L": the accumulated damage state in slight - complete is more than $30 \%$

"Moderate, M" : the accumulated damage state in moderate - complete is more than $50 \%$

"High, $\mathrm{H}$ " the accumulated damage state in extensive - complete is more than $30 \%$

"Intensive, I" : the accumulated damage state in extensive - complete is more than $50 \%$

According to the damage level of each structural type, the PGA $(\mathrm{g})$ intensity for all the structural types are shown in Table 4.

\subsection{Building Occupancy}

The building occupancy implicitly represents the importance level of the building. However, the importance level is a site dependence and qualitative aspects of human knowledge. There are nine types of building occupancy in Chiang Rai Municipality, as seen in Table 1. Hence, it needs reasoning process to quantify the importance level. It was previously evaluated and weighted by using Analytical Hierarchy Process (AHP) [25]. Figure 8 shows the criteria for the pairwise comparisons of building exposures computed by integrating building occupancy, likelihood of human casualty, economic importance and the value of property. Table 7 shows the ranked buildings occupancy based on the AHP. From the table, the most important building is 
hospital buildings and the commercial building is the least important. The ranked order was applied for fuzzy membership as shown in Fig. 9.
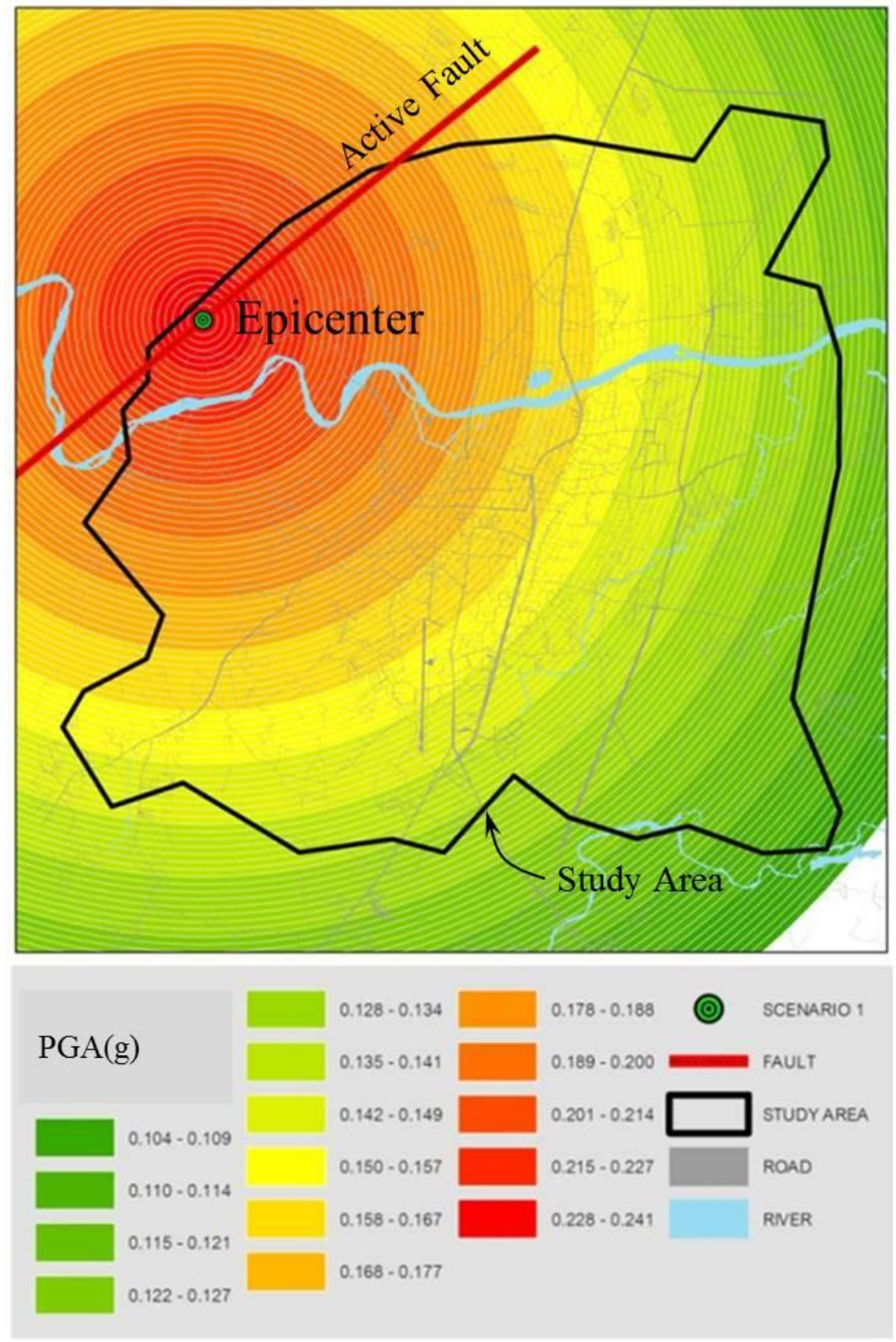

Fig. 6. Peak ground acceleration distribution under an assumed earthquake. 


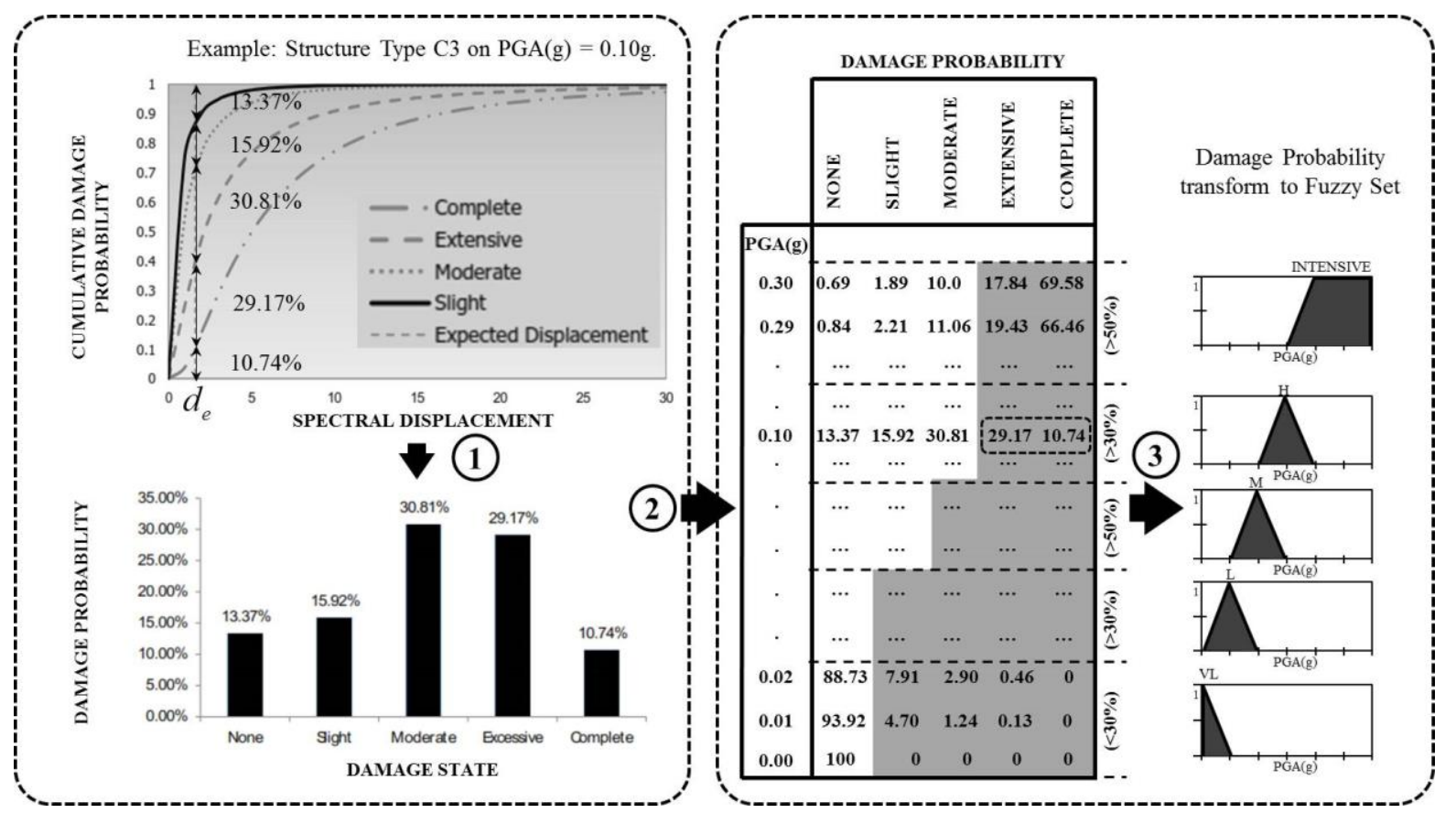

Fig. 7. The PGA(g) Fuzzy Model.

Table 4. PGA(g) intensity for all the structural types based on the damage level.

\begin{tabular}{lccccc}
\hline Structure & \multicolumn{5}{c}{ PGA $(\mathrm{g})$} \\
Type & $\mathrm{VL}$ & $\mathrm{L}$ & $\mathrm{M}$ & $\mathrm{H}$ & $\mathrm{I}$ \\
\hline C1 & $<0.05$ & $0.05-0.07$ & $0.07-0.10$ & $0.10-0.15$ & $>0.15$ \\
C2 & $<0.06$ & $0.06-0.08$ & $0.08-0.12$ & $0.12-0.17$ & $>0.17$ \\
C3 & $<0.05$ & $0.05-0.07$ & $0.07-0.10$ & $0.10-0.16$ & $>0.16$ \\
W1 & $<0.08$ & $0.08-0.19$ & $0.19-0.24$ & $0.24-0.26$ & $>0.26$ \\
W2 & $<0.07$ & $0.07-0.09$ & $0.09-0.14$ & $0.14-0.23$ & $>0.23$ \\
S1 & $<0.05$ & $0.05-0.09$ & $0.09-0.13$ & $0.13-0.16$ & $>0.16$ \\
S2 & $<0.06$ & $0.06-0.10$ & $0.10-0.14$ & $0.14-0.17$ & $>0.17$ \\
S3 & $<0.05$ & $0.05-0.06$ & $0.06-0.08$ & $0.08-0.12$ & $>0.12$ \\
URM & $<0.07$ & $0.07-0.13$ & $0.13-0.15$ & $0.15-0.17$ & $>0.17$ \\
W2C3 & $<0.07$ & $0.07-0.10$ & $0.10-0.16$ & $0.16-0.23$ & $>0.23$ \\
W1C3 & $<0.07$ & $0.07-0.14$ & $0.14-0.16$ & $0.16-0.25$ & $>0.25$ \\
\hline
\end{tabular}


Goal

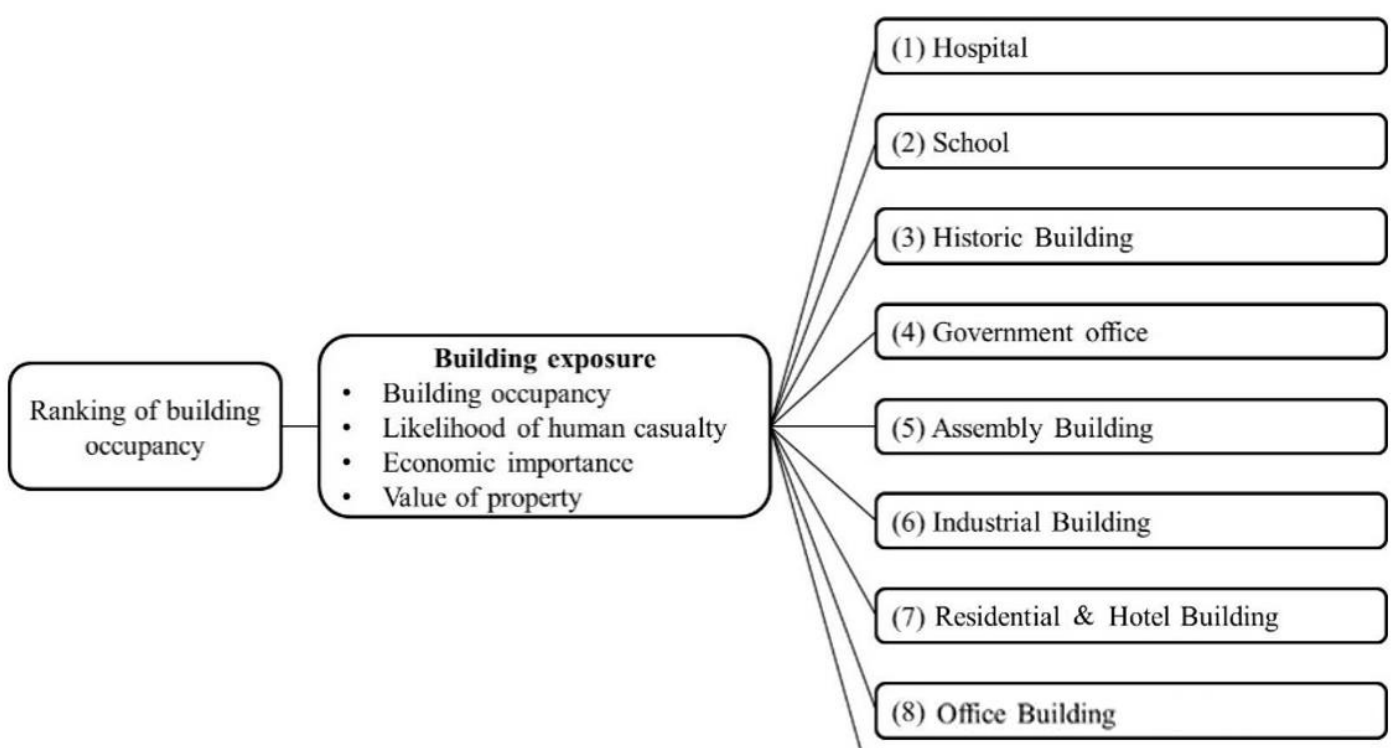

(9) Commercial Building \& Other

Fig. 8. AHP hierarchy diagram for ranking of building occupancy.

Table 5. Ranking of the building occupancy [25].

\begin{tabular}{llllll}
\hline No. & Building Occupancy & Weight, $\%$ & $\begin{array}{l}\text { Crisp } \\
\text { Ranking }\end{array}$ & $\begin{array}{l}\text { Fuzzy } \\
\text { Ranking }\end{array}$ & Membership value \\
\hline 1 & Hospital Building & 30.43 & 1 & $(1,1,3)$ & $(0.875,1,1)$ \\
2 & School Building & 21.11 & 2 & $(1,2,3)$ & $(0.75,0.875,1)$ \\
3 & Historic Building & 11.63 & 3 & $(2,3,4)$ & $(0.625,0.75,0.875)$ \\
4 & Government office & 9.14 & 4 & $(3,4,5)$ & $(0.5,0.625,0.75)$ \\
5 & Assembly Building & 8.46 & 5 & $(4,5,6)$ & $(0.375,0.5,0.625)$ \\
6 & Industrial Building & 5.66 & 6 & $(5,6,7)$ & $(0.25,0.375,0.5)$ \\
7 & Residential \& Hotel Building & 5.29 & 7 & $(6,7,8)$ & $(0.125,0.25,0.375)$ \\
8 & Office Building & 4.72 & 8 & $(7,8,9)$ & $(0,0.125,0.25)$ \\
9 & Commercial \& Other Building & 5.57 & 9 & $(8,9,9)$ & $(0,0,0.125)$ \\
\hline
\end{tabular}

Com Office Res Fac Assb Gov Temp School Hosp

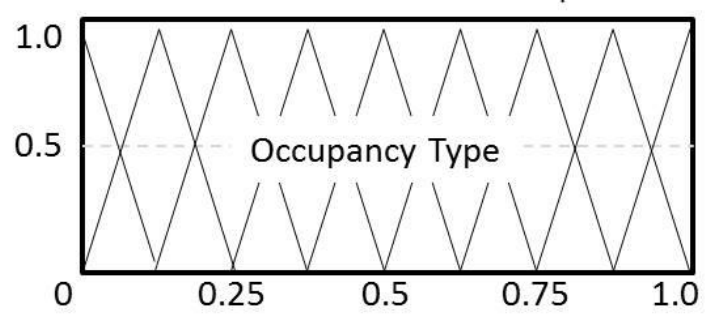

Fig. 9. Member ship function of building occupancy. 


\section{Inference and Defuzzification}

\subsection{Building Damageability}

Building damageability (Level 2 in Fig. 2) was determined by integrating the Peak Ground Acceleration fuzzy set and the building vulnerability fuzzy set as shown in Fig. 10. The total 25 fuzzy rules for fuzzy inference relying on the expert judgments basis was used to estimate the building damage, as shown in Table 6. From the table, based on the IF-THEN conditions, the results of the buildings damageability classification are expressed as "N: none damage", "L: light damage", "M: moderate damage", "H: heavy damage" and "S: severe damage" categories. Using the defuzzification based on the weighted average method shown in Eq. (4), the building damageability score was obtained. The building damageability score of buildings in the study area is shown in Fig. 11. Due to the stronger ground motion near the epicentre, it illustrates that the maximum damage mostly occurred near the epicenter. At the same location, better performed seismic structural type, e.g. steel and wood structure buildings, show smaller damageability score compared with the concrete buildings.

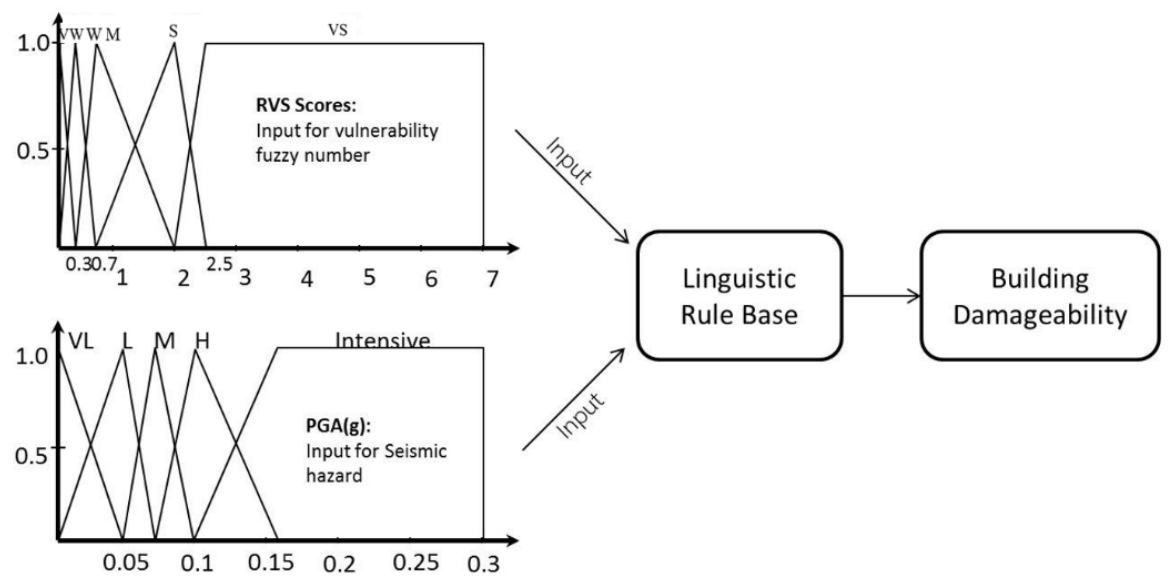

Fig. 10. Determination of the building damageability.

Table 6. Fuzzy associative memory (FAM) for building damage.

\begin{tabular}{clllll}
\hline \multirow{2}{*}{ Building vulnerability } & \multicolumn{5}{c}{ PGA $(\mathrm{g})$} \\
\cline { 2 - 6 } & VL & L & M & H & I \\
\hline Very Strong, VS & N & N & L & M & H \\
Strong, S & N & L & M & M & H \\
Moderate, M & L & M & M & H & H \\
Weak, W & M & M & H & H & S \\
Very Weak, VW & M & H & H & S & S \\
\hline
\end{tabular}




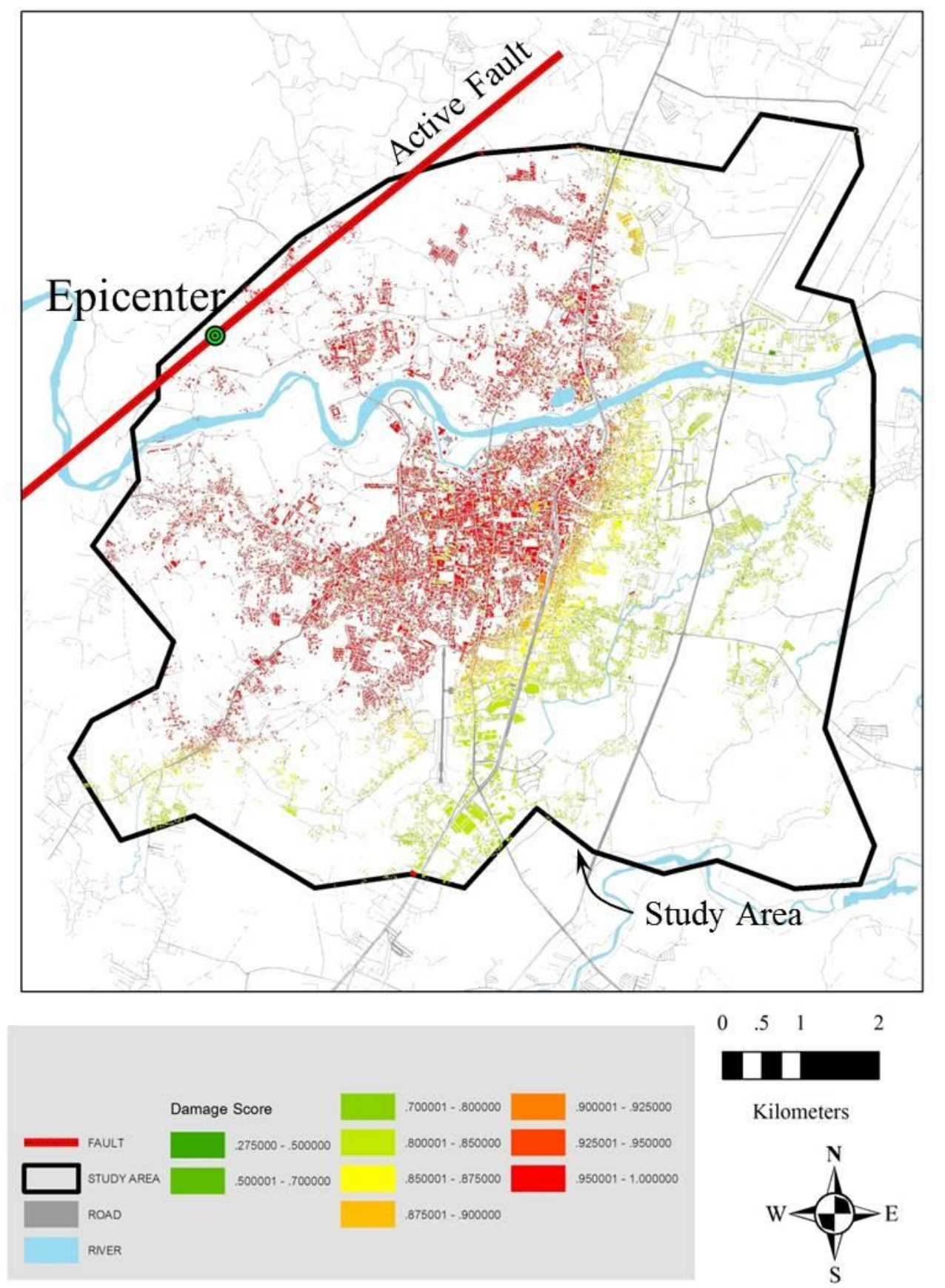

Fig. 11. Building damage score in the study area.

\subsection{Total Risk Scores}

Finally, as seen in Fig. 12, the total risk score was computed by integrating the building importance and the building damageability scores. First, the result of the damageability score of every building in the area shown in Fig. 11 was transferred to the fuzzy input based on the damage type descriptions of BSSC [26]. 


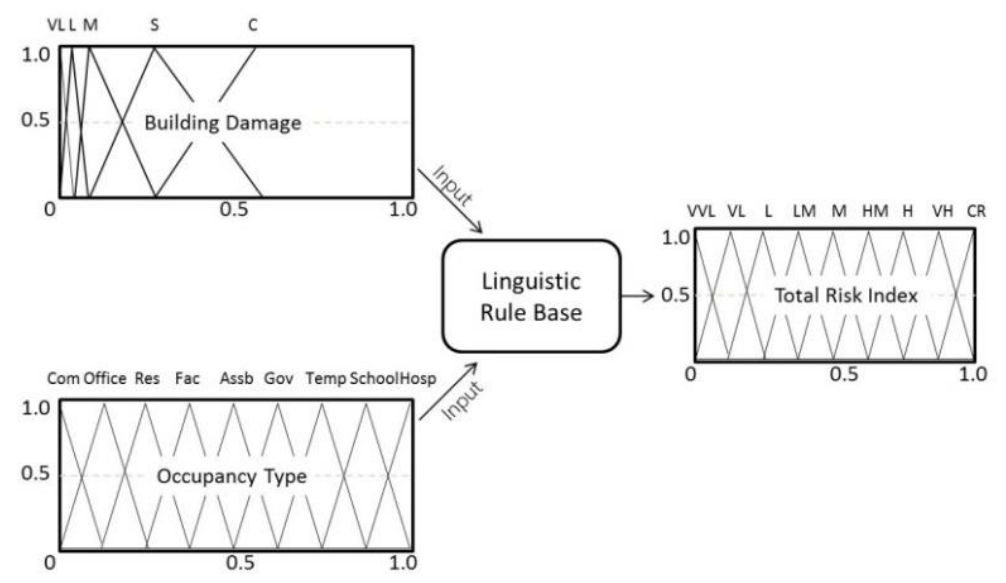

Fig. 12. Flowchart of the Total Risk score

The fuzzification for the total risk index contains totally 45 linguistic rules, as presented in Table 7 . The results from the fuzzification is expressed in terms of fuzzy words in proper sentences (statement) such as "Very Very Low, VVL ", "Very light, VL", "Light, L", "Light-moderate, LM", "Moderate, M", "Highmoderate, HM", "High, H”, "Very-high" and "Critical, CR" , respectively. Then, defuzzification using Eq.(4) was performed for the Total Risk Score of buildings. The scores are spatially presented in Fig. 13. Although the high damageability buildings are at the closer location to the epicenter, as seen in Fig. 11, it can be seen from Fig. 13 that the high seismic risk buildings are located evenly on the area.

Table 7. Fuzzy associative memory (FAM) for total risk score.

\begin{tabular}{cccccc}
\hline \multirow{2}{*}{ Type } & \multicolumn{5}{c}{ Damage } \\
\cline { 2 - 6 } & VL & L & M & S & C \\
\cline { 2 - 6 } & VVL & VVL & VL & L & LM \\
Commercial & VVL & VL & L & LM & M \\
Office & VL & L & LM & M & M \\
House & L & LM & M & M & HM \\
Factory & LM & M & M & HM & HM \\
Assembly & M & M & HM & HM & H \\
Gov. office & M & HM & HM & H & VH \\
Temple & HM & HM & H & VH & CR \\
School & HM & H & VH & CR & CR \\
Hospital & & & & &
\end{tabular}

To present the seismic retrofitting prioritization based on the total risk score, the analysis result examples are shown in Table 8 with six selected buildings. From the table, the hospital building is the first priority needed to retrofits with the damageability score of 0.808 and the total risk score of 0.962 . The factory equally has the damageability score of 0.808 , the total risk score is 0.625 due to the low building importance. In the other hand, the school building with the damageability score of 0.222 , with the high importance, the total risk score is as high as 0.823 . Temple and historic buildings also can be classified as the high seismic risk building which also need to be retrofit with priority. The house buildings are the less priority for the risk mitigation. 


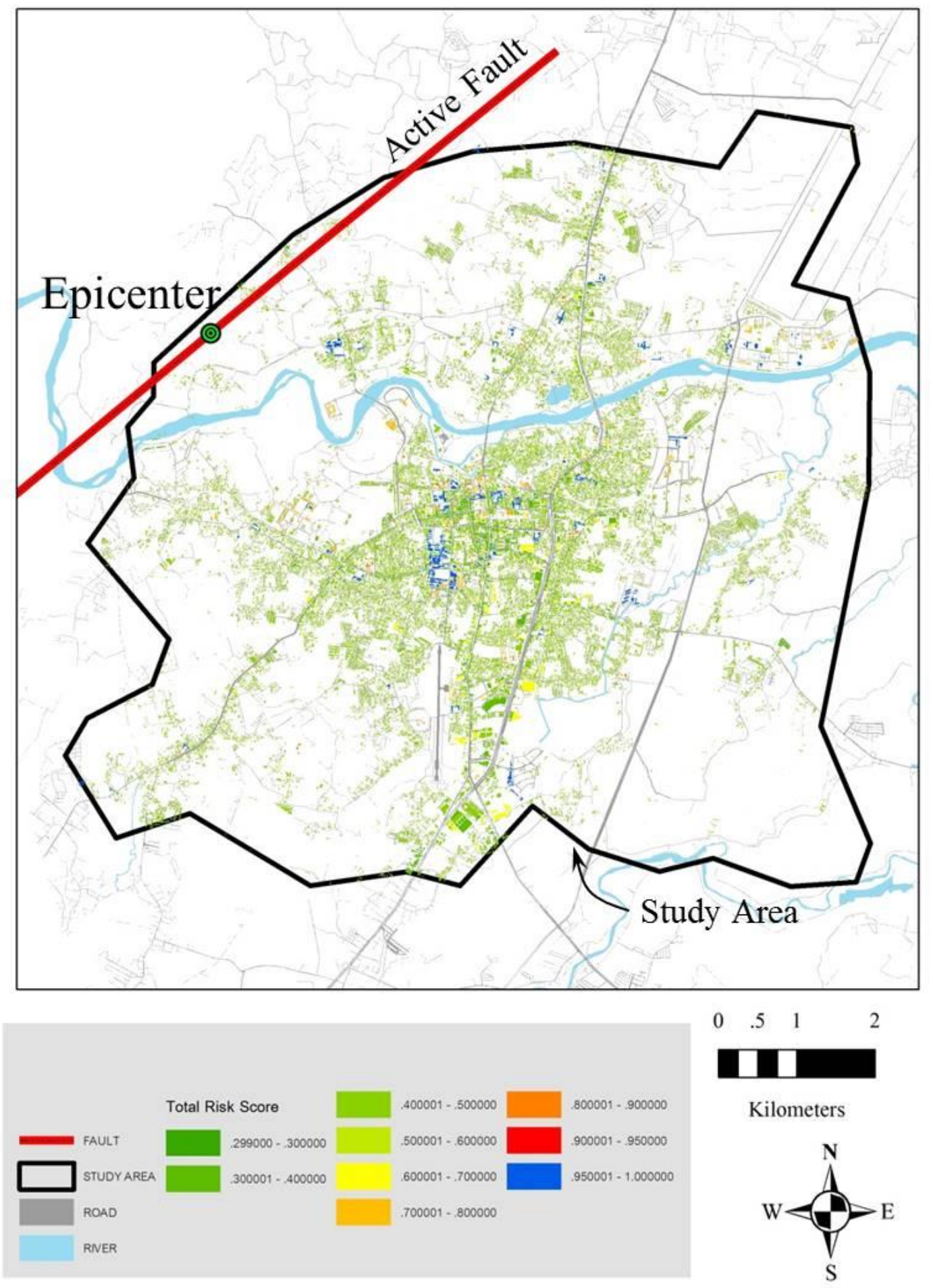

Fig. 13. Total Risk Score in Chiang Rai City, Thailand. 
Table 8. Example building with Total Risk Score from fuzzy model.

\begin{tabular}{lcccccc}
\hline \multicolumn{1}{c}{ Building Name } & Type & Occupancy & $\begin{array}{c}\text { RVS, } \\
\text { Final } \\
\text { Score }\end{array}$ & PGA(g) & $\begin{array}{c}\text { Damageabil } \\
\text { ity } \\
\text { Score }\end{array}$ & $\begin{array}{c}\text { Total Risk } \\
\text { Score }\end{array}$ \\
\hline Hospital, id. 49785 & C3 & Hospital & 3.6 & 0.169 & 0.808 & 0.962 \\
Local School, id. 38959 & W1C3 & School & 4.6 & 0.143 & 0.222 & 0.823 \\
Temple, id. 664 & W2C3 & Historic & 2.7 & 0.182 & 0.581 & 0.864 \\
Government, id.38906 & C3 & Gov. Office & 2.6 & 0.133 & 0.657 & 0.750 \\
Factory, id. 25972 & C3 & Industrial & 2.1 & 0.178 & 0.808 & 0.625 \\
House, id. 11883 & W1 & Residential & 6.6 & 0.114 & 0.145 & 0.408 \\
\hline
\end{tabular}

\section{Conclusions}

This paper performs earthquake risk evaluation of buildings in Chiang Rai City, Thailand using Fuzzy risk model. Uncertainty and fuzzy decision model of three input variables were developed including seismic hazard, building vulnerability and building importance. Finally, the three variable containing uncertainty were inferenced and defuzzified for the total risk score of the buildings in the study area. From the results, the total risk score of buildings can be obtained and prioritization on seismic retrofitting can be made. The study results show that the prioritization should be paid to hospital and school buildings considered as the high seismic risk building. Although, the damageability score is small, but the total risk is high due to the high importance. House can be considered as a low seismic risk building compared with other type of occupancies. From the study, it can be concluded that the proposed approach is a useful method for the earthquake risk evaluation containing the vague or unclear definition.

\section{Acknowledgements}

The authors would like to acknowledge Faculty of Engineering, Chiang Mai University for supports under Research Assistant scholarship (RA) and the Graduate School of Chiang Mai University for financial support under Teacher Assistant and Research Assistant scholarship (TA/RA). The project is financially supported by TRF Research Scholar (RSA6280039) and TRF Senior Research Scholar (RTA6280012).

\section{References}

[1] A. Coburn and R. Spence, Earthquake Protection, Chichester-NewYork: Willey Inc., 2011.

[2] S. Balassanian, "Seismic risk reduction strategy in the XXI Century," in Earthquake Hazard and Seismic Risk Reduction. Kluwer Academic Publishers, 2000.

[3] Z. Sen, "Supervised fuzzy logic modeling for building earthquake hazard assessment," Expert Systems with Applications, vol. 38, pp. 14564-14573, Nov.-Dec. 2011.

[4] M. Erdik, "Earthquake risk assessment," Bulletin of Earthquake Engineering, vol. 15, pp. 5055-5092, 2017.

[5] B. R. Ellingwood, "Earthquake risk assessment of building structures," Reliability Engineering and System Safety, vol. 74, pp. 251-262, 2001.

[6] L. A. Zadeh, "Fuzzy sets," Information and Control, vol. 8, pp. 338-353, 1965.

[7] K. Saicheur and C. Hansapinyo, "Structural repair prioritization of buildings damaged after earthquake using fuzzy logic model," Journal of Disaster Research, vol. 11, no. 3, pp. 559-565, 2016.

[8] S. K. Deb and G. T. Kumar, "Seismic damage assessment of reinforced concrete buildings using fuzzy logic," presented at The 13 th World Conference on Earthquake Engineering, Vancouver, B.C., Canada, 2004.

[9] Z. Sen, "Rapid visual earthquake hazard evaluation of existing buildings by fuzzy logic modeling," Expert Systems with Applications, vol 37, pp. 5653-5660, Aug. 2010.

[10] M. G. D’Urso, D. Masi, G. Zuccaro, and D. D. Gregorio, "Multicriteria fuzzy analysis for a GIS-based management of earthquake scenarios," Computer-Aided Civil and Infrastructure Engineering, vol. 33, pp. 165179, 2018.

[11] H. Haoxiang, C. Maolin, and L. Yonhwei, "Earthquake damage assessment for RC structures based on fuzzy sets," Mathematical Problems in Engineering, vol. 2013, pp. 1-11, 2013. 
[12] Z. Boutaraa, N. Caterina, A. Ahmed, and S. Olivier, "Buildings vulnerability assessment and damage seismic scenarios at urban scale: Application to Chlef City (Algeria)," KSCE Journal of Civil Engineering, vol. 22, pp. 1-13, 2018.

[13] K. Vahdat, N. Smith, and G. Amiri "Fuzzy multicriteria for developing a risk management system in seismically prone areas," Socio-Economic Planning Sciences, vol. 48, pp. 235-248, Dec. 2014.

[14] S. Tesfamariam and M. Saatcioglu, "Seismic risk assessment of reinforced concrete buildings using fuzzy rule based modeling," presented at The 14th World Conference on Earthquake Engineering, Beijing, China, 2008.

[15] A. Teraphan, "Seismic wave from Mae Lao Earthquake 5 May 2014," in Proceedings of the Mae Lao Earthquake in Chiangrai Lesson to Learned, Bangkok, Thailand, 2014, p. 35.

[16] C. Palasri and A. Ruangrassamee, "Probabilistic seismic hazard maps of Thailand," Journal of Earthquake and Tsunami, vol. 4, pp. 369-386, 2010.

[17] T. Ornthammarath, P. Warnitchai, K. Worakanchana, S. Zaman, R. Sigbjörnsson, and C. Lai, "Probabilistic seismic hazard assessment for Thailand," Bulletin of Earthquake Engineering: Official Publication of the European Association for Earthquake Engineering, vol. 9, pp. 367-394, Apr. 2011.

[18] K. Saicheur and C. Hansapinyo, "Seismic loss estimation and reduction after structural rehabilitation in Chiang Rai City," Walailak Journal of Science and Technology, vol. 14, no. 6, pp. 485-499, 2017.

[19] Federal Emergency Management Agency, Rapid Visual Screening of Buildings for Potential Seismic Hazards: A Handbook FEMA P-154, 3rd ed. Washington, DC, USA: Applied Technology Council (ATC), Federal Emergency Management Agency, 2015.

[20] Federal Emergency Management Agency, Rapid Visual Screening of Buildings for Potential Seismic Hazards: Supporting Documentation FEMA P-155, 3rd ed. Washington, DC, USA: Applied Technology Council (ATC), Federal Emergency Management Agency, 2015.

[21] R. P. Nanda and D. R. Majhi, "Rapid seismic vulnerability assessment of building stocks for developing countries," KSCE Journal of Civil Engineering, vol. 18, no. 7, pp. 2218-2226, 2014.

[22] R. R. Youngs, S. J. Chiou, W. J. Silva, and J. R. Humphrey, "Strong ground motion attenuation relationships for subduction zone earthquakes," Seismological Research Letters, vol. 68, pp. 58-73, 1997.

[23] P. Warnitchai, C. Sangarayakul, and S. A. Ashford, "Seismic hazard in Bangkok due to distant earthquakes," in Proceeding of the 2nd Multi-lateral Workshop on Development of Earthquake and Tsunami Disaster Mitigation Technologies and their Integration for the Asia-Pacific Region, Kobe, Japan, 2000.

[24] Federal Emergency Management Agency-FEMA, Multi-Hazard Loss Estimation Methodology—Earthquake Module: HAZUS-MH MR1 Advanced Engineering Building Module Technical and User's Manual, 3rd ed. Washington, DC, USA: Federal Emergency Management Agency, 2003.

[25] K. Saicheur, C. Hansapinyo, P. Damrongchai, and P. Teingburanatham, "Multi-criteria decision making for seismic retrofitting of reinforced concrete school buildings in Chiang Mai Municipal," in Proceedings of the Eighteenth National Convention on Civil Engineering, The Engineering Institute of Thailand, Chiang Mai, Thailand, 2013.

[26] BSSC, "Prestandard and commentary for the seismic rehabilitation of buildings," FEMA-356, Building Seismic Safety Council, Federal Emergency Management Agency, Washington, D.C., 2000. 